\title{
DERIVATION OF HIGHLY MEFLOQUINE-RESISTANT LINES FROM PLASMODIUM FALCIPARUM IN VITRO
}

\author{
SHEILA A. PEEL, STEPHEN C. MERRITT, \\ JEAN HANDY, AND RALPH S. BARIC \\ Department of Epidemiology, and Department of Microbiology and Immunology, University of North \\ Carolina, Chapel Hill, Chapel Hill, North Carolina; Department of Microbiology, George \\ Washington University, Washington, DC
}

\begin{abstract}
Serial passage of a multidrug-resistant clone of Plasmodium falciparum in concentrations of mefloquine hydrochloride ranging from 30 to $2,400 \mathrm{ng} / \mathrm{ml}$ resulted in the derivation of increasingly resistant parasite lines in vitro. Parasite lines isolated in mefloquine concentrations greater than $300 \mathrm{ng} / \mathrm{ml}$ demonstrated increased vacuolization, enhanced pigment production, and increased growth rates as compared with the progenitor clone, W2-mef. Although microdilution incorporation assays demonstrated that the $50 \%$ inhibitory concentration ( $\mathrm{IC}_{50}$ ) of mefloquine were similar for all lines, the $\mathrm{IC}_{90}, \mathrm{IC}_{95}$, and $\mathrm{IC}_{99}$ levels were significantly increased. Growth rate assays performed in $5 \%$ hematocrit suspensions demonstrated different levels of mefloquine resistance among these lines. Under these conditions the most resistant line, Mef 2.4, grew efficiently in approximately 10 fold higher concentrations of mefloquine than the progenitor clone W2-mef. Analysis of drug susceptibility profiles to mefloquine hydrochloride, chloroquine diphosphate, quinine sulfate, and halofantrine hydrochloride indicated that selection for high levels of mefloquine resistance had resulted in significant increases in resistance to halofantrine and increased sensitivity to chloroquine. The phenotypic changes demonstrated in the most resistant line, Mef 2.4, reflect a multidrug resistant-like phenotype, and appear to mimic changes recently reported in drug susceptibility profiles of recrudescent isolates following mefloquine treatment failures in Thailand.
\end{abstract}

Plasmodium falciparum, the cause of the most lethal form of human malaria, is widespread throughout the tropical world and is one of the most challenging issues in modern tropical health. Since vaccines are not available, chemotherapy represents one of the few methods of control for the 1.6 billion humans at risk of infection. ${ }^{1} \mathrm{Me}$ floquine (Lariam ${ }^{\star}$; Hoffman LaRoche, Nutley, NJ) has been approved for chemoprophylaxis and chemotherapy for those at risk of infection with chloroquine-resistant or multiple drug-resistant strains of $P$. falciparum. ${ }^{2}$ Reports of treatment failures from Thailand, ${ }^{3-6}$ naturally occurring foci of resistance in the Philippines and West Africa, ${ }^{7.8}$ the induction of resistance in cloned parasites in vitro, 9.10 and possible cross-resistance to quinine and halofantrine, however, cast doubt on the long-term efficacy of mefloquine, ${ }^{6.11}$ or any of the existing antimalarials, against drug-resistant $\boldsymbol{P}$. falciparum.

The genetic mechanisms that mediate resistance to mefloquine are poorly understood. Rodent malaria easily developed resistance to mefloquine, especially when chloroquine resistance was derived first. ${ }^{12,13} \mathrm{~A}$ four- to six-fold increased resistance to mefloquine was readily de- veloped in vitro from a clonal population of $P$. falciparum by continuous drug pressure. The clonal line exhibited two-fold increased resistance to halofantrine and increased susceptibility to chloroquine. ${ }^{10}$ In addition, mefloquine resistance in $P$. falciparum in vitro and $P$. yoelii in vivo were reversed by the neuroleptic drug penfluridol. ${ }^{13.14}$ These findings have led to the suggestion that mefloquine resistance may be phenotypically similar to the enhanced drug efflux demonstrated by multidrug-resistant (MDR) tumor cell lines. Resistance in these MDR cell lines is mediated by the activity of an ATP-dependent efflux pump termed the P-glycoprotein. ${ }^{15,16}$

Recent evidence suggests that mefloquine resistance may also be mediated by point mutations and/or gene amplification events in a P-glycoprotein homolog, the pfmdrl gene, and in perhaps one or more additional genes. ${ }^{14,17,18}$ The mefloquine resistance phenotype, however, was not linked to the amplified $p f m d r l$ gene following genetic analysis, ${ }^{19}$ indicating that the molecular basis for mefloquine and chloroquine resistance has not been established and will require additional study. In this paper, we report the isolation and characterization of a series of progressively 
more resistant lines of $P$. falciparum in vitro that will be useful in the study of the mechanisms of mefloquine resistance.

\section{MATERIALS AND METHODS}

\section{Parasite lines}

The parasite clones W2 and W2-mef, derived at the University of North Carolina, ${ }^{10,20}$ were gifts from Dr. Ayoade Oduola (now of the University of Ibadan, Ibadan, Nigeria). The W2 clone was originally obtained by single erythrocyte micromanipulation from a $50 \%$ mixture of the Sierra Leone I/CDC and Indochina III/CDC parasite lines. The mefloquine resistant clone W2mef was derived by continuous low-dose mefloquine pressure from the multidrug-resistant but mefloquine-sensitive W2 clone. ${ }^{10 .} 20$

\section{Cultivation of parasites}

Parasite lines were grown using modifications of standard methods. ${ }^{21-23}$ Stock cultures were maintained in sealed $25-\mathrm{cm}^{2}$ tissue culture flasks (Corning Glass Works, San Francisco, CA) in a total volume of $5 \mathrm{ml}$ of $6 \%$ erythrocyte suspension in RPMI 1640 medium (Sigma, St. Louis, MO) supplemented with $10 \%$ heat inactivated human plasma, $2 \mu \mathrm{g} / \mathrm{ml}$ of hypoxanthine (Sigma) and $28 \mathrm{mM} \mathrm{NaHCO}_{3}$ (Sigma). The erythrocytes used were human type A-positive collected in citrate phosphate dextrose (CPD), CPD-A1, or CPD-A1-Adsol (Fort Bragg, Fayetteville, NC and American Red Cross, Durham, NC). Cultures were grown in the absence of antibiotics, gassed with $5 \% \mathrm{CO}_{2}, 5 \% \mathrm{O}_{2}$, and $90 \% \mathrm{~N}_{2}$ (National Welders, Raleigh, NC), and shaken at $50 \mathrm{rpm}$ in an environmental orbital incubator (New Brunswick Scientific, Edison, $\mathrm{NJ}$ ) at $37^{\circ} \mathrm{C}$, or grown as static cultures at $37^{\circ} \mathrm{C}$. Morphology and parasitemia were assessed by microscopic examination of thin blood smears stained with Leuko-Stat (Fisher Scientific, Atlanta, GA). Cultures were routinely diluted into fresh erythrocytes to a 0.1 $0.2 \%$ parasitemia every $3-4$ days. Final parasitemia ranged from $4 \%$ to $15 \%$ depending on the isolate or clone.

\section{Selection for increased mefloquine resistance}

Mefloquine hydrochloride was a gift from the Division of Experimental Therapeutics, Walter
Reed Army Institute of Research (WRAIR), (Washington, DC). Stock solutions were prepared by dissolving mefloquine hydrochloride in $70 \%$ ethanol to give a concentration of $1 \mathrm{mg} / \mathrm{ml}$. The solution was incubated at $37^{\circ} \mathrm{C}$ for $30 \mathrm{~min}$ and stored at $4^{\circ} \mathrm{C}$ protected from light. The appropriate concentration of stock solution was diluted into medium daily for parasite cultivation in the presence of drug.

The original W2-mef line had been selected for resistance to $40 \mathrm{ng} / \mathrm{ml}$ of mefloquine. ${ }^{10}$ To select for increased mefloquine resistance, W2mef was continuously exposed to $30 \mathrm{ng} / \mathrm{ml}$ of mefloquine until the clone demonstrated morphology and growth rates equivalent to the parental line by microscopic examination. By increasing the concentration by $5-10 \mathrm{ng} / \mathrm{ml}$ increments, lines were derived that were resistant to $55 \mathrm{ng} / \mathrm{ml}$ of mefloquine. Continuous drug pressure protocols were unsuccessful in selecting for resistance greater than $55 \mathrm{ng} / \mathrm{ml}$.

Protocols were then developed for selection of increased resistance using modifications of techniques described for the selection for highly resistant MDR tumor cell lines and rodent malarias. ${ }^{24,}{ }^{25} \mathrm{High}$-dose relapse protocols were initiated as follows. Parasites were cultivated in the presence of drug until no parasites were detected on a thin smear, then drug pressure was discontinued. Upon demonstration of healthy ring formation and parasite growth equivalent to controls, cultures were again pressured 3-5 times with the same concentration of drug until a culture was derived that tolerated a higher mefloquine dosage than the parental line as assayed by smear morphology. Parasite lines were developed as described above at each progressively higher concentration until lines that tolerated 75, $100,150,300,400,1,200$, and $2,400 \mathrm{ng} / \mathrm{ml}$ of mefloquine (designated Mef 75, Mef 100, Mef 150, Mef 300, Mef 400, Mef 1.2, and Mef 2.4, respectively,) were derived over an 18 -month period. Selection levels exceeding $2,400 \mathrm{ng} / \mathrm{ml}$ of mefloquine were not successful because of the limits of drug solubility. Aliquots of passage lines that were frozen and stored in liquid nitrogen for future studies are shown in Figure 1.

\section{Drug susceptibility testing}

Parasite stabilates were thawed and maintained in the absence of drug for up to one year prior to drug susceptibility assays. Parasites were 
washed two times in medium without exogenous hypoxanthine, or were cultivated for one week prior to assay in medium without hypoxanthine supplementation. The semiautomated microdilution technique was used as an index of antimalarial activity. ${ }^{26}$ Briefly, 96-well, flat-bottomed microtiter plates were prepared with serial dilutions of drug in duplicate over 520-fold or 1,024-fold concentration ranges. Parasitized erythrocytes at a $1.5 \%$ hematocrit with an initial parasitemia of $0.25-0.4 \%$ were added to each well, the plates were incubated at $37^{\circ} \mathrm{C}$ in $5 \%$ $\mathrm{CO}_{2}, 5 \% \mathrm{O}_{2}$, and $90 \% \mathrm{~N}_{2}$ for $24 \mathrm{hr}$, pulse labeled with ${ }^{3} \mathrm{H}$-hypoxanthine $(0.5 \mu \mathrm{Ci} /$ well, specific activity $1 \mathrm{mCi} / \mathrm{mM}$; ICN Biomedicals, Inc., Costa Mesa, CA) for $18 \mathrm{hr}$, and harvested at $42-44 \mathrm{hr}$ onto glass fiber filters (Whatman LabSales, Hillsboro, OR) using a Mash II cell harvester (MA Bioproducts, Inc., Walkersville, MD). The 50\%, $90 \%, 95 \%$, and $99 \%$ inhibitory concentrations $\left(\mathrm{IC}_{50},{ }_{90},{ }_{95}\right.$, and ${ }_{99}$, respectively, $)$ of mefloquine hydrochloride (WRAIR), chloroquine diphosphate (Sigma), quinine sulfate (Sigma), and halofantrine hydrochloride (WRAIR) were determined by nonlinear regression analysis of concentration-response data. ${ }^{26}$

Microscopic assays were also used for an independent determination of inhibitory concentrations of mefloquine. Briefly, 96-well, flat-bottomed microtiter plates (Nunc, Inc., Naperville, IL) were prepared with serial dilutions of drug concentrations in triplicate ranging from $1.2 \mathrm{ng} /$ $\mathrm{ml}$ to $1,250 \mathrm{ng} / \mathrm{ml}$ of mefloquine. Parasite suspensions of a $1.5 \%$ hematocrit with an initial $0.2 \%$ parasitemia were added, the plates were gassed, and incubated at $37^{\circ} \mathrm{C}$. Smears were made at $44 \mathrm{hr}$, stained, parasites were counted, and the inhibitory concentration values were calculated. Mean $\mathrm{IC}_{50}$ and $\mathrm{IC}_{90}$ determinations were compared with data from assays set up simultaneously by the ${ }^{3} \mathrm{H}$-hypoxanthine microdilution method.

\section{Morphologic growth curves}

Growth rate assays were performed on the W2 and W2-mef clones and the Mef 300 and Mef 2.4 passage lines in medium containing mefloquine at the approximate $\mathrm{IC}_{50}(20 \mathrm{ng} / \mathrm{ml})$ and $\mathrm{IC}_{95}(100 \mathrm{ng} / \mathrm{ml})$ level of the Mef 2.4 passage line. Briefly, $10 \mathrm{ml}$ of $5 \%$ hematocrit suspensions of control and drug-treated cultures were prepared with an initial parasitemia of $1.3-1.5 \%$.

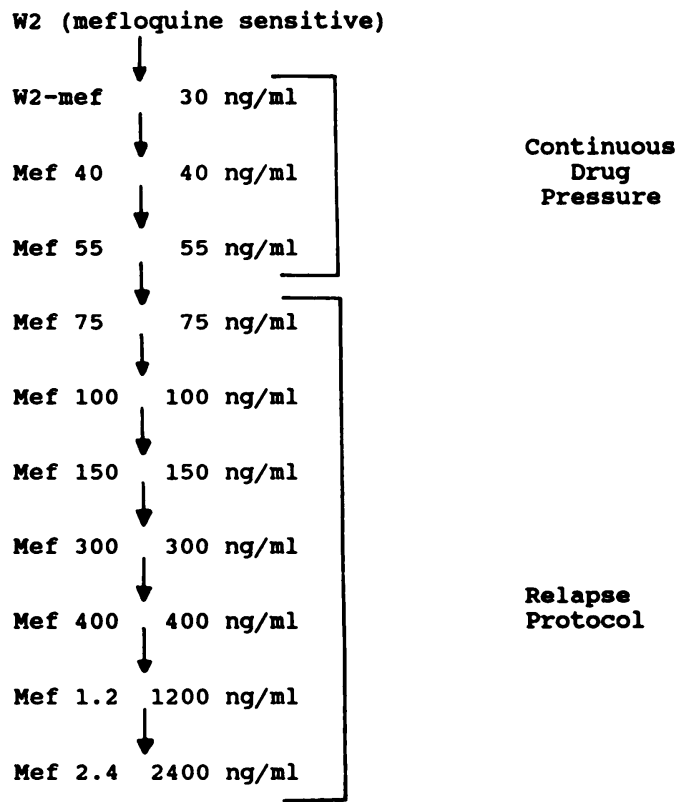

FIGURE 1. Selection protocol for the derivation of highly resistant passage lines of Plasmodium falciparum in vitro with mefloquine (Mef) hydrochloride. Parasite lines shown were stabilated and stored for future studies.

Thin blood smears were taken every $12 \mathrm{hr}$ for $72 \mathrm{hr}$. The percent parasitemia was determined by counting 2,000-10,000 erythrocytes depending on the percent parasitemia of the culture, and growth curves were constructed. Photographs were taken with Tungsten Balanced Tech Pan film (Eastman Kodak, Rochester, NY) on a Nikon (Melville, NY) FXA microscope. The original magnification was either 1,000 $\times$ (Figure 2A) or 1,400 $\times$ (Figure $2 \mathrm{~B}-\mathrm{F}$ ).

\section{Exponential growth rates $(R)$}

The growth rate was analyzed as previously described by the following equation:

$$
R=\frac{\ln A_{2}-\ln A_{1}}{t_{2}-t_{1}}
$$

where $A_{1}$ and $A_{2}=$ the number of parasites per milliliter of blood at times $t_{1}$ and $t_{2}$, respectively. ${ }^{23}$

\section{Morphometric studies}

To determine the degree of vacuolization of the parasite clones and lines, the total parasite 

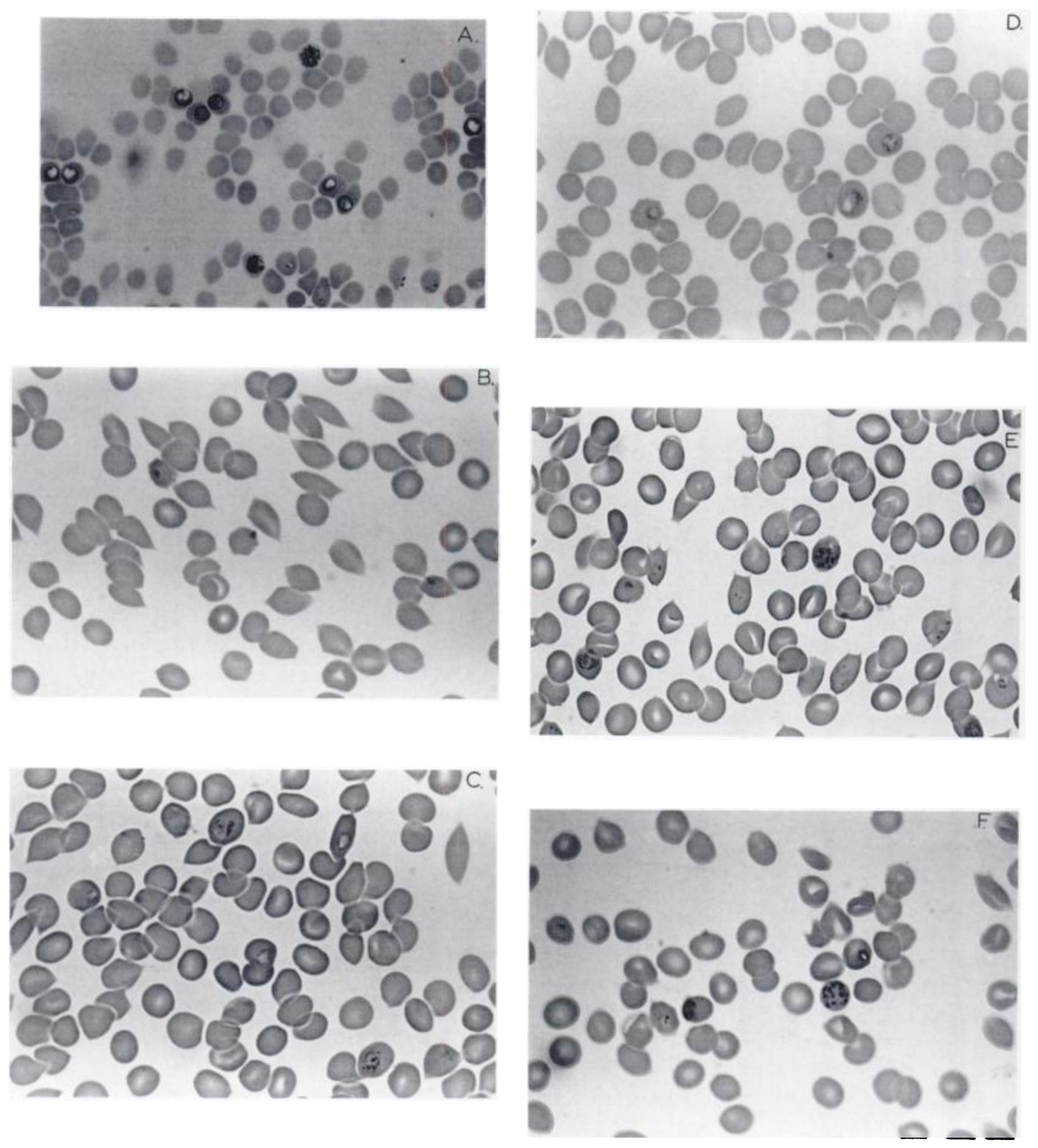

FIGURE 2. Modified Giemsa-stained thin blood smears demonstrating parasite morphology. A, enlarged vacuole formation and increased hemozoin production in Mef 2.4 line. The clones W2 (B) and W2-mef (C), and the passage lines Mef 300 (D) and Mef 2.4 (E) were cultivated in $100 \mathrm{ng} / \mathrm{ml}$ of mefloquine hydrochloride. The Mef 2.4 line was cultivated in $200 \mathrm{ng} / \mathrm{ml}$ of mefloquine hydrochloride (F). (Original magnification $\times 1,000$ for $A$, and $\times 1,400$ for $B-F)$.

and vacuole areas of 25-40 midstage trophozoites were measured using a software morphometry system (Image Measure; Phoenix Technology, Federal Way, WA) with an image processor (FG-100-AT; Imaging Technology, Woburn, MA). The mean total parasite and vacuole areas and standard deviation were calculated for $\mathbf{W} 2$, W2-mef, and Mef 2.4.

\section{Statistical analysis}

All inhibitory concentration measurements, parasite area, vacuole area, merozoite numbers 
per schizont, and growth rates were statistically analyzed, and presented as mean \pm standard deviation. A one-way analysis of variance with a pos hoc contrast to compare group means was used to evaluate the statistical significance of measurements. ${ }^{27}$

RESULTS

\section{Selection for highly resistant parasite lines}

The W2-mef clone had exhibited stable mefloquine resistance for three years in the absence of drug when selection protocols for higher resistance levels were initiated. The basic approach for selection of the progressively resistant passage lines is depicted in Figure 1. Since W2-mef did not tolerate $40 \mathrm{ng} / \mathrm{ml}$ of drug, the final selection dosage that was used in the derivation of this clone, ${ }^{10}$ mefloquine pressure was resumed at a concentration of $30 \mathrm{ng} / \mathrm{ml}$. Parasite growth rates decreased and changes in parasite morphology were observed for the first several weeks of drug pressure. Morphologic changes noted in mefloquine treated cultures included 1) enlargement, swelling, and occasional pigmentation of the ringstage cytoplasm, 2) vacuolization, enlargement, and rarefaction of the chromatin mass, 3) compact, small, diffusely stained trophozoites marked by vacuolization with dispersal of pigment, 4) mature schizonts that were extremely disorganized with reduced numbers of merozoites that appeared to be disintegrated, and 5) vacuolated erythrocytes. After several weeks of passage in this drug concentration, resistant parasite lines appeared that were morphologically similar to parental controls, and exhibited growth rates equivalent to controls. The mefloquine concentration was then increased. Under the continuous drug pressure protocols described in the Materials and Methods, parasites adapted to $55 \mathrm{ng} /$ $\mathrm{ml}$ of mefloquine within 20 weeks. Attempts to isolate lines resistant to levels greater than $55 \mathrm{ng} /$ $\mathrm{ml}$ were unsuccessful.

To circumvent this problem, we initiated relapse protocols based on approaches used to isolate highly resistant MDR tumor cells. ${ }^{16}$ Drug concentrations were increased (see Figure 1 for parasite lines that were stabilated) as follows. Initially, parasites were cultivated in the presence of drug for no more than two to three days when parasitemias decreased below the limits of detectability $(<0.001 \%)$. Detection of par- asites in culture generally occurred two to four days following cessation of drug pressure. By the fifth re-exposure to drug at concentrations of $300 \mathrm{ng} / \mathrm{ml}$ of mefloquine, parasites survived for five to seven days prior to decreasing below detectable limits, and required nine-days incubation in drug-free medium before they were again detected. Parasite lines were eventually isolated that tolerated doses of 1,200 and 2,400 $\mathrm{ng} / \mathrm{ml}$ for 14 days with continued low-level schizogony, after which they were not detectable in culture until after 31-days incubation in the absence of drug.

\section{Morphologic alterations and growth rate analysis}

Morphologic alterations on thin blood smears were observed with the derivation of the Mef 300 line and seen in subsequent parasite lines. An enlarged vacuole was seen in the trophozoite stage and at early chromatin division of the schizont stage (Figure 2A). To document the increased vacuolization in Mef 2.4, the total parasite and vacuole areas of midstage trophozoites of W2, W2-mef, and Mef 2.4 were determined. The mean \pm SD parasite areas for W2, W2-mef, and Mef 2.4 were $12.57 \pm 2.92 \mu \mathrm{m}^{2}, 12.19 \pm$ $2.03 \mu \mathrm{m}^{2}$, and $12.10 \pm 2.10 \mu \mathrm{m}^{2}$, respectively. No significant differences were noted among the means $(P=0.726)$. The mean $\pm S D$ vacuole areas of W2, W2-mef, and Mef 2.4 were $0.74 \pm$ $0.57 \mu \mathrm{m}^{2}, 1.59 \pm 0.83 \mu \mathrm{m}^{2}$, and $5.23 \pm 1.73$ $\mu \mathrm{m}^{2}$, respectively. The mean total vacuole area encompassed $5.9 \%$ of the total parasite area of W2, $13.0 \%$ of the area of W2-mef, and $43.2 \%$ of the area of Mef 2.4. Significant increases in total vacuole area were noted in W2-mef and Mef 2.4 as compared with W2 $(P<0.05)$, and between W2-mef and Mef $2.4(P<0.001)$. Increased pigment formation was also noted, and has persisted as a permanent morphologic alteration (Figure 2A).

The exponential growth rates ( $R$ values) were determined for the progenitor clone, W2-mef, and the Mef 2.4 line. Significant differences were noted in the mean \pm SD $R$ values for Mef 2.4 $(1.89 \pm 0.22)$ as compared with those for W2mef $(1.34 \pm 0.13)(P=0.05)$. Merozoite numbers per schizont were determined to ascertain whether increased merozoite formation had resulted during the derivation of Mef 2.4. The mean number of merozoites per schizont was not signifcantly different among W2 (18.9 \pm 1.9$)$, W2-mef 


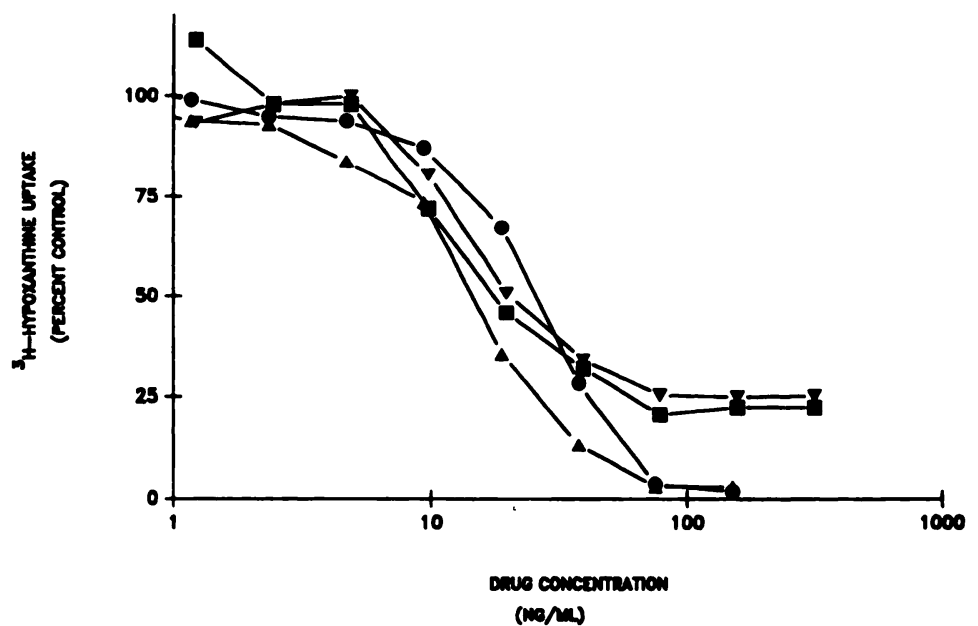

FIGURE 3. Comparative dose-response curves of the clone W2-mef and the passage lines of Plasmodium falciparum to mefloquine hydrochloride. In vitro susceptibility profiles of W2-mef (0), Mef $300(\Delta)$, Mef 1.2 $(\nabla)$, and Mef $2.4(\nabla)$ were generated using ${ }^{3} \mathrm{H}$-hypoxanthine incorporation as an index of parasite growth. Control counts per minute ranged from 20,000 to 30,000 .

$(18.1 \pm 2.5)$, and Mef $2.4(20.1 \pm 2.0)(P=$ 0.116).

\section{Determination of inhibitory concentrations}

The dose-response curves of the W2-mef, Mef 300, Mef 1.2, and Mef 2.4 lines against mefloquine as determined by ${ }^{3} \mathrm{H}$-hypoxanthine incorporation are shown in Figure 3. The doseresponse curves of the Mef 1.2 and 2.4 lines reflect a broadening of the curve that does not return to baseline even when assayed against $500 \mathrm{ng} / \mathrm{ml}$ of mefloquine. The Mef 2.4 line was a more vigorous parasite line, since the initial parasitemia had to be significantly reduced (twofold compared with those of W2 or W2-mef) for radiometric assay or parasite overgrowth significantly affected results. Table 1 lists the mean \pm SD determinations of the estimated
$\mathrm{IC}_{50},{ }_{90}, 95$, and 99 values for mefloquine against W2, W2-mef, Mef 300, Mef 1.2, and Mef 2.4. No significant change in the $\mathbf{I C}_{50}$ was noted in Mef $300(P=0.606)$, Mef $1.2(P=0.764)$, or Mef 2.4 $(P=0.704)$ as compared with W2-mef. The means of the estimated $\mathrm{IC}_{90}, 95$, and 99 values were not significantly different between $\mathrm{W} 2$ mef and Mef $300(P=0.175)$. Significant differences in these values, however, were noted in Mef 1.2 and Mef 2.4 as compared with W2mef and Mef $300(P=0.001)$. No significant difference was noted in the $\mathrm{IC}_{90}(P=0.559)$ or IC $_{95}(P=0.444)$ values for Mef 1.2 as compared with Mef 2.4. The mean $\mathrm{IC}_{90}$ values for Mef 1.2 and Mef 2.4 demonstrated a 1.5 -fold increase, and the mean $\mathrm{IC}_{95}$ demonstrated a 1.9-fold increase as compared with W2-mef and Mef 300 . The mean $\mathrm{IC}_{9}$, was increased 2.8-fold for Mef 1.2 and 2.3-fold for Mef 2.4 as compared with

TABLE 1

Comparative in vitro susceptibility profiles of the Plasmodium falciparum clones W2 and W2-mef, and the Mef 300. Mef 1.2, and Mef 2.4 lines to mefloquine hydrochloride*

\begin{tabular}{lcccc}
\hline & \multicolumn{4}{c}{ Estimated inhibitory concentration (ng/ml) } \\
\cline { 2 - 5 } Clone or line & \multicolumn{1}{c}{$\mathrm{IC}_{\text {so }}$} & \multicolumn{1}{c}{$\mathrm{IC}_{90}$} & \multicolumn{1}{c}{$\mathrm{IC}_{9 s}$} & $\mathrm{IC}_{99}$ \\
\hline W2 & $4.89 \pm 0.72$ & $11.61 \pm 0.67$ & $15.74 \pm 1.46$ & $33.76 \pm 5.52$ \\
W2-mef & $15.17 \pm 4.02$ & $44.04 \pm 9.57$ & $60.23 \pm 11.93$ & $117.65 \pm 19.80$ \\
Mef 300 & $13.88 \pm 1.77$ & $38.82 \pm 1.90$ & $56.42 \pm 2.93$ & $128.92 \pm 7.74$ \\
Mef 1.2 & $14.42 \pm 3.15$ & $67.01 \pm 2.77$ & $113.84 \pm 9.48$ & $339.10 \pm 45.50$ \\
Mef 2.4 & $16.13 \pm 4.38$ & $64.84 \pm 1.91$ & $108.02 \pm 14.20$ & $283.07 \pm 46.39$ \\
\hline
\end{tabular}

- Values are means \pm SD of at least three separate determinations (two serial dilutions per determination). 
TABLE 2

Comparison of radiometric and microscopic methods for determination of estimated inhibitory concentrations (IC) of the Plasmodium falciparum Mef 2.4 line against mefloquine*

\begin{tabular}{lcc}
\hline IC & Radiometric & Microscopic \\
\hline $\mathrm{IC}_{\text {s0 }}$ & $14.96 \pm 3.94$ & $15.60 \pm 0.56$ \\
$\mathrm{IC}_{90}$ & $66.50 \pm 6.25$ & $85.40 \pm 7.17$ \\
\hline
\end{tabular}

* Values are the mean $\pm \mathrm{SD}$ in $\mathrm{ng} / \mathrm{ml}$.

the means for W2-mef and Mef 300 . These results demonstrated that resistance to mefloquine in these passage lines had increased significantly.

Microscopic assays were performed for comparison since previous studies reported a lack of correlation between radiometric and microscopic assays against mefloquine. ${ }^{9}$ The $\mathrm{IC}_{50}$ and IC $_{90}$ values for Mef 2.4 against mefloquine determined in parallel by both methods are presented in Table 2. No significant differences were noted in the mean $\mathrm{IC}_{50}$ or $\mathrm{IC}_{90}$ values obtained by the two methods $(P=0.115)$.

Parasite lines had been derived that clearly tolerated increased concentrations of mefloquine, yet their $\mathrm{IC}_{50}$ values were unchanged as determined by both radiometric and microscopic dilution assays. Their elevated $\mathrm{IC}_{95}$ and $\mathrm{IC}_{99}$ values were consistent with increased resistance. We therefore sought to determine whether mefloquine tolerance resulted from a small resistant subpopulation that persisted in culture and accounted for sufficient ${ }^{3} \mathrm{H}$-hypoxanthine incorporation to result in the trailing endpoint of the dose-response curve, but not enough incorporation to increase the $\mathrm{IC}_{50}$ of the entire culture.

Assay data for the Mef 1.2 and 2.4 lines were reanalyzed using a modification of the logisticlogarithmic function that permits the evaluation of a biphasic concentration-response relationship of a mixed culture. ${ }^{20}$ The results are shown in Figure 4. The first $\mathrm{IC}_{\text {so }}$ values were similar (13.78 \pm 1.08 for Mef 1.2 and $15.58 \pm$ 1.50 for Mef 2.4) to those presented in Figure 3 and Table 1 . The curves had a trailing endpoint that did not return to baseline even at a mefloquine concentration of $1,200 \mathrm{ng} / \mathrm{ml}$ (higher dilutions were not possible because of solubility limitations). The values calculated by the curve-fitting program using the assumption that the curve would return to baseline were $1,484.18$ \pm 534.64 for Mef 1.2 and 1,430.96 \pm 539.24 for Mef 2.4, respectively. These results suggested that if a highly resistant subpopulation were present, it would exhibit a very high IC $_{50}$, and would represent a minor percentage of the parasite population. Determination of a second IC $_{50}$ for a presumed resistant subpopulation, however, could not be determined with confidence.

\section{Growth curve analysis}

The results of the radiometric and microscopic assays, showing an $\mathrm{IC}_{30}$ value of approximately $15 \mathrm{ng} / \mathrm{ml}$ of mefloquine, were puzzling since the parasite lines had demonstrated very efficient growth in $55 \mathrm{ng} / \mathrm{ml}$ of mefloquine during isolation of the passage series. Growth rates of mefloquine-sensitive W2, the progenitor clone, W2-mef, and the passage lines Mef 300 and Mef 2.4 were analyzed in the presence and absence of drug using conditions that reflected the original selection protocol $(10-\mathrm{ml}$ suspensions of a 5\% hematocrit). Cultures were inoculated with parasitemias of 1.3-1.5\% in mefloquine concentrations ranging from $0 \mathrm{ng} / \mathrm{ml}$ to $200 \mathrm{ng} / \mathrm{ml}$. These concentrations were chosen to approximate the range of $\mathrm{IC}_{50}$ to $\mathrm{IC}_{99}$ values of Mef 2.4 against mefloquine by radiometric and microscopic dose-response assays (Tables 1 and 2). The results of these experiments are shown in Figure 5.

Under conditions in which control cultures reached maximum parasitemia within $36 \mathrm{hr}$, growth of the mefloquine-sensitive W2 clone was rapidly inhibited in either $20 \mathrm{ng} / \mathrm{ml}$ or 100 $\mathrm{ng} / \mathrm{ml}$ of mefloquine (Figure 5A). Parasite morphology demonstrated collapsed trophozoites that appeared tight and darkly stained (Figure 2B). Parasitemia decreased to levels less than $0.001 \%$ by $72 \mathrm{hr}$. In contrast, W2-mef, Mef 300 , and Mef 2.4 exhibited growth rates equivalent to untreated controls when cultivated in $20 \mathrm{ng} /$ $\mathrm{ml}$ of mefloquine (Figure 5B-D). The W2-mef line was rapidly eliminated from culture in the presence of 50 or $100 \mathrm{ng} / \mathrm{ml}$ of mefloquine within 3-4 days (Figure 5B). Parasite morphology demonstrated small, vacuolated, diffusely stained trophozoites with marked dissolution of pigment (hemozoin), and schizonts with reduced numbers of disintegrating merozoites (Figure 2C). The Mef 300 line grew efficiently in $50 \mathrm{ng} / \mathrm{ml}$ of mefloquine, but exhibited reduced growth rates in the presence of $100 \mathrm{ng} /$ 

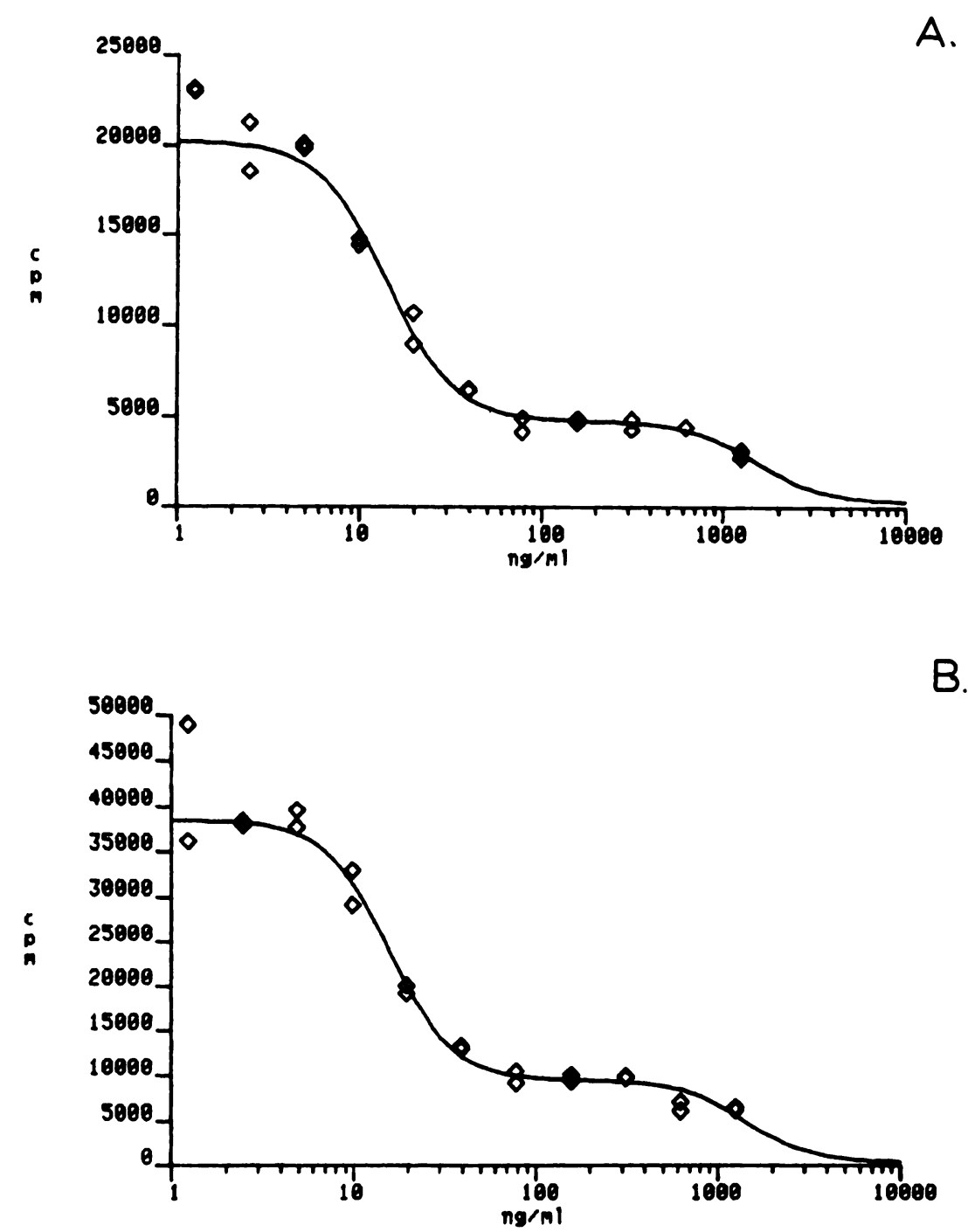

FiGURE 4. Dose concentration response analysis of the A, Mef 1.2 and B, Mef 2.4 lines of Plasmodium falciparum against mefloquine hydrochloride. Dose response was analyzed using a modification of the logisticlogarithınic function that permits evaluation of a biphasic concentration-response relationship. ${ }^{20}$ Control counts per minute (cpm) ranged from 20,000 to 38,000 .

ml of mefloquine (Figure 5C). Morphology similar to that described for W2-mef was detected after cultivation in $100 \mathrm{ng} / \mathrm{ml}$ of mefloquine for three days (Figure 2D). Parasitemia eventually decreased below limits of detectability $(<$ $0.001 \%$ ) after one week. The most surprising result of these studies was the growth of Mef 2.4 at rates equivalent to controls in the presence of $100 \mathrm{ng} / \mathrm{ml}$ of mefloquine (Figure 5D). Parasite morphology appeared to be unaffected by this concentration of drug (Figure 2E); how- ever, the number of merozoites per schizont was significantly reduced $(11.3 \pm 1.4$ as compared with $20.1 \pm 2.0$ for untreated controls; $P<$ 0.001 ). Cultivation of Mef $2.4 \mathrm{in} 200 \mathrm{ng} / \mathrm{ml}$ of mefloquine resulted in a reduction in parasite growth (Figure 5D). Although merozoite numbers were greatly reduced $(6.8 \pm 1.9$ as compared with $20.1 \pm 2.0$ for untreated controls: $P$ $<0.001$ ), schizont formation continued at these drug levels (Figure 2F). 
A

B

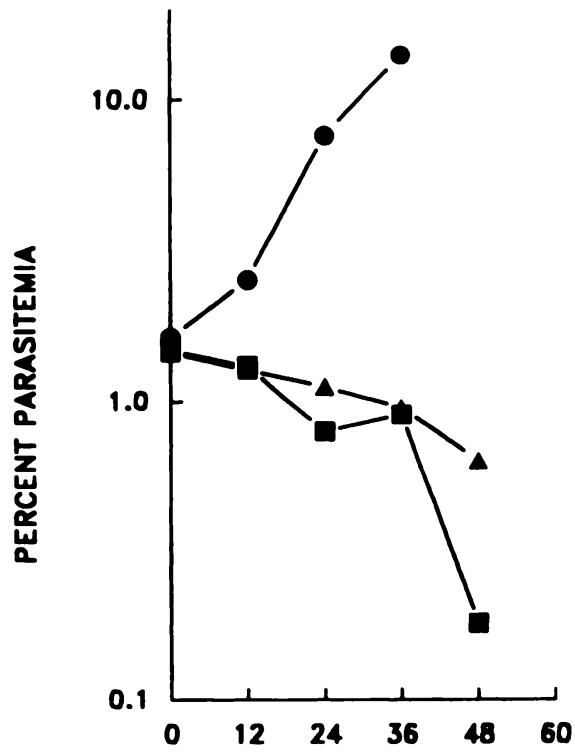

HOURS IN CULTURE

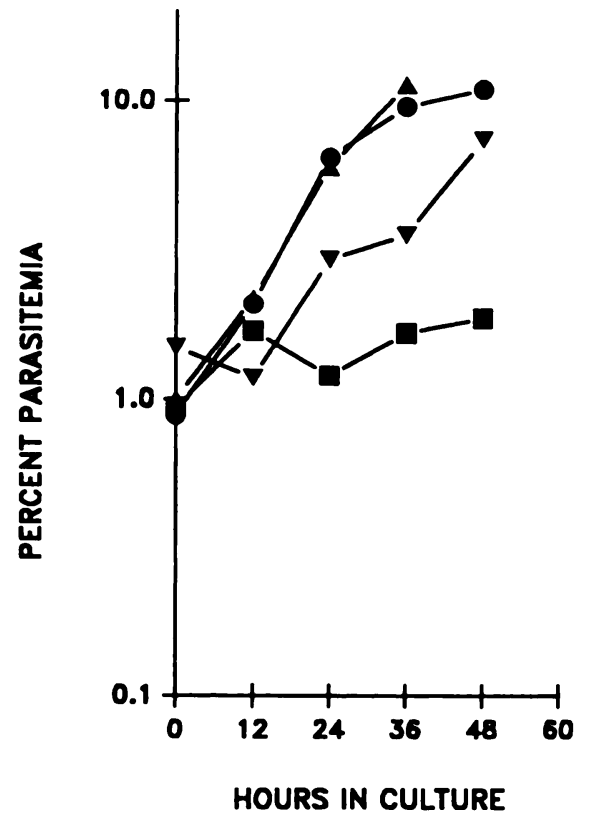

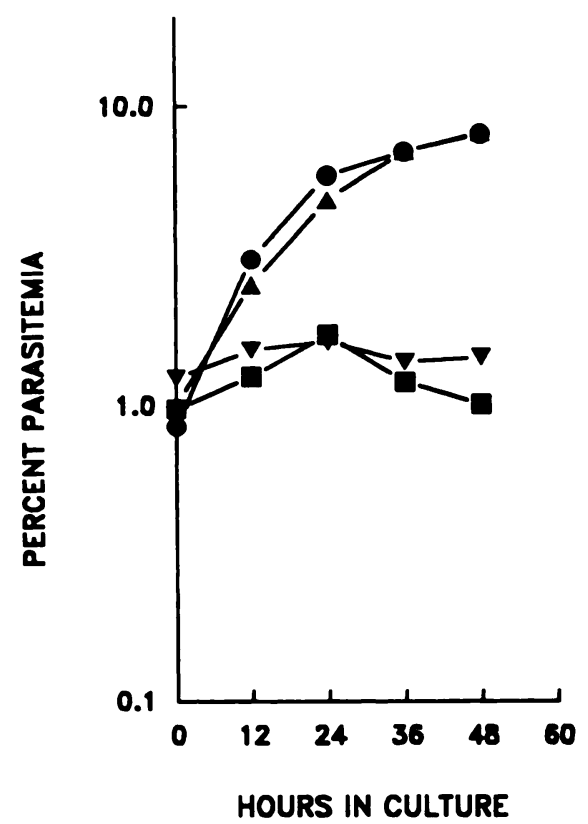

C

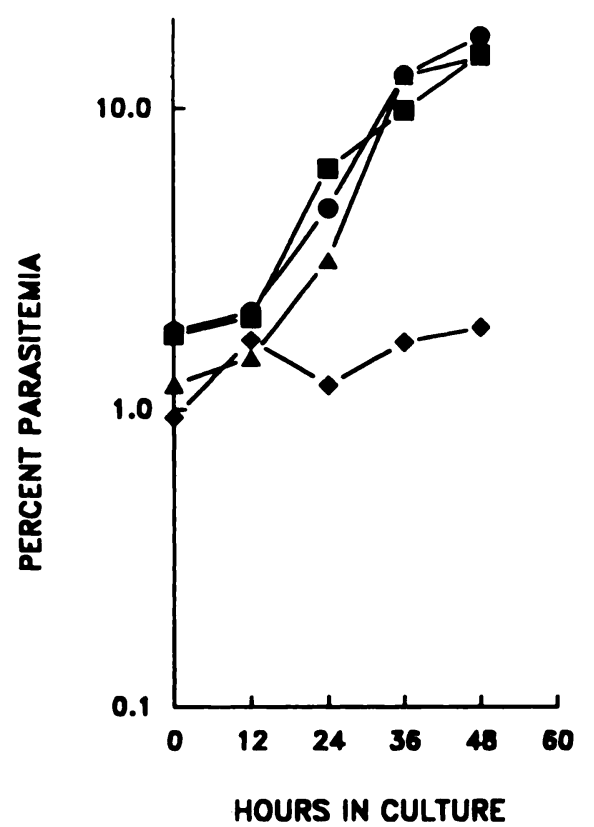

Figure 5. Growth curves of A, the mefloquine-sensitive clone W2, B, the mefloquine-resistant clone W2mef, C, the Mef 300 line, and D, the Mef 2.4 line of Plasmodium falciparum cultivated in the presence of $0 \mathrm{ng} /$ $\mathrm{ml}(0), 20 \mathrm{ng} / \mathrm{ml}(\Delta), 50 \mathrm{ng} / \mathrm{ml}(\nabla), 100 \mathrm{ng} / \mathrm{ml}(\square)$, or $200 \mathrm{ng} / \mathrm{ml}(\Delta)$ of mefloquine hydrochloride. 
TABLE 3

Fifty percent inhibitory concentration $\left(I C_{s \alpha}\right)$ determinations for chloroquine diphosphate, halofantrine hydrochloride, and quinine sulfate with Plasmodium falciparum clones, W2 and W2-mef, and the Mef 2.4 line*

\begin{tabular}{llll}
\hline & & & $I_{\text {so }}$ (ng/ml) \\
\cline { 2 - 4 } Clone or line & Chloroquine & Halofantrine & Quinine \\
\hline W2 & $98.87 \pm 2.38$ & $0.38 \pm 0.02$ & $66.21 \pm 14.50$ \\
W2-mef & $63.81 \pm 0.277$ & $1.45 \pm 0.22$ & $55.82 \pm 7.86$ \\
Mef 2.4 & $49.25 \pm 6.18$ & $3.31 \pm 1.46$ & $77.03 \pm 9.93$ \\
\hline
\end{tabular}

- Values are means \pm SD of at least three separate determinations (two separate dilutions per determination).

\section{Cross-resistance}

Since an approximate 1.4 -fold increased susceptibility to chloroquine and an approximate 2.3-fold increased resistance to halofantrine were noted in the W2-mef line compared with its multidrug-resistant parent $\mathrm{W} 2,{ }^{10}$ drug susceptibility to chloroquine, quinine, and halofantrine was assayed in the resistant passage lines. The $\mathrm{IC}_{50}$ determinations for W2, W2-mef, and Mef 2.4 against chloroquine diphosphate, quinine sulfate, and halofantrine are shown in $\mathrm{Ta}$ ble 3. These data indicated little difference in susceptibility to quinine in the Mef 2.4 line as compared with W2 and W2-mef $(P=0.199)$. In contrast, the estimated $\mathrm{IC}_{\text {so }}$ determinations indicated a 1.3-fold increased sensitivity to chloroquine $(P<0.05)$, and an approximate 2.3-fold increased resistance to halofantrine ( $P$ $<0.05$ ) as compared with W2-mef.

\section{DISCUSSION}

A series of progressively more resistant lines of $P$. falciparum was isolated by cultivation in mefloquine concentrations ranging from $30 \mathrm{ng} /$ $\mathrm{ml}$ to $2,400 \mathrm{ng} / \mathrm{ml}$. Parasite lines were derived that grow efficiently in $100-200 \mathrm{ng} / \mathrm{ml}$, and that tolerated concentrations of $2,400 \mathrm{ng} / \mathrm{ml}$ for extended periods. Persistence in $2,400 \mathrm{ng} / \mathrm{ml}$ for periods of up to 14 days with low level schizogony suggested that the parasite could tolerate in vitro dosages approaching the mean \pm SD peak plasma concentrations $(1.12 \pm 0.3 \mu \mathrm{g} / \mathrm{ml})$ measured in humans following a $1,500-\mathrm{mg}$ dose. ${ }^{28}$ To our knowledge, no other mefloquine-resistant lines have been derived that tolerate drug doses in vitro that approach pharmacologic levels in humans.

The apparent increased resistance of the passage lines to mefloquine under culture conditions was not confirmed by increased IC $_{50}$ determinations generated by radiometric or microscopic assays. Comparison of the growth curves (Figure 5) with the assay data (Tables 1 and 2) suggests a likely explanation for this anomaly. The ${ }^{3} \mathrm{H}$ hypoxanthine assay used $1.5 \%$ hematocrit suspensions, while growth curve analysis used 5\% hematocrit suspensions, which were also used in maintenance cultures and drug selection protocols. Since mefloquine has been found to bind extensively to phospholipids and erythrocyte membranes with high affinity, ${ }^{29}$ and to hemoglobin with low affinity, ${ }^{30}$ the percent hematocrit can greatly alter drug bioavailability to the parasite.

The dose-response curve has been shown to be dramatically modulated by an increased percent hematocrit. ${ }^{11}, 31$ The results of growth rate analysis using $5 \%$ hematocrit suspensions clearly indicated that lines had been derived that demonstrated increased resistance as compared with the W2-mef clone. The Mef 300 line grew in $50 \mathrm{ng} / \mathrm{ml}$ of mefloquine while W2-mef did not, and the Mef 2.4 line grew in concentrations $(100-200 \mathrm{ng} / \mathrm{ml})$ that significantly inhibited Mef 300. These results supported those of a previous study, which demonstrated a three-fold discrepancy between IC $_{50}$ determinations measured by microscopic versus radiometric assays in different percent hematocrit suspensions. ${ }^{9}$ Our results also suggest that growth rate analysis using suspensions of higher hematocrit may better predict resistance to mefloquine, and perhaps other extremely lipophilic drugs, under physiologic conditions. Interestingly, researchers in a Thai study were unable to use in vitro susceptibility profiles of pretreatment isolates (generated by ${ }^{3} \mathrm{H}$-hypoxanthine assays) to predict subsequent mefloquine treatment failures. ${ }^{\circ}$

The increased vacuole formation observed in parasite lines with dosages exceeding $300 \mathrm{ng} / \mathrm{ml}$ was consistent with studies that demonstrated rapid swelling of the parasite food vacuole following exposure to extremely high $(50 \mu \mathrm{g} / \mathrm{ml})$ 
concentrations of mefloquine. ${ }^{32}$ Although slight vacuolization is seen at times during in vitro cultivation of $P$. falciparum, the Mef 2.4 line has produced significantly larger vacuoles $(43 \%$ of the total parasite area) than those seen in other clones and lines cultivated in the laboratory. It is interesting to note that increased vacuolization and increased numbers of lysosome-like vacuoles have been noted in MDR tumor cell lines following selection with cytotoxic concentrations of lipophilic antitumor agents. ${ }^{33} \mathrm{~A}$ hypothesis offered to explain these findings in MDR tumor cells is that vesicular compartmentalization and altered targeting of drug away from cellular targets may play a role in drug resistance mechanisms. ${ }^{34}$

Increased growth rates have been associated with the development of resistant parasites in vitro and in vivo, ${ }^{35}$ although it is not clear what parasite processes contribute to this phenomenon. The increased growth demonstrated by the Mef 2.4 line could not be attributed to increased merozoite production since merozoite formation was not significantly different from either W2 or W2-mef. An abbreviated life cycle, and/ or enhanced invasion of erythrocytes may contribute to enhanced growth. Enhanced pigment production may also be associated with increased growth since rapidly metabolizing parasites may sequester increased amounts of hemozoin. Alternatively, it may be associated with an altered heme polymerase activity. This enzyme is thought to function in the sequestration of the toxic heme moiety, ferriprotoporphyrin IX, by polymerizing it into hemozoin. ${ }^{36.37}$ Chloroquine, amodiaquine, and quinidine have been shown to block heme polymerization in vitro, suggesting that this enzyme may be a target for quinoline-containing antimalarials. ${ }^{37}$

A current controversial hypothesis is that resistance to chloroquine and mefloquine in $P$. falciparum may be similar to the MDR phenotype described in MDR tumor cell lines. ${ }^{38}$ The classic MDR phenotype characterized by changes in sensitivity to a broad spectrum of related and unrelated drugs, however, has not yet been established in $P$. falciparum. A single well-documented exception may be the in vitro induction of mefloquine resistance in the multidrug-resistant clone, W2, which resulted in altered susceptibility patterns to chloroquine and its analogue halofantrine, which are drugs within the same broad chemical class. ${ }^{10}$ The deri- vation of the Mef 2.4 line from W2-mef also resulted in additional increases in sensitivity to chloroquine and resistance to halofantrine, providing additional support for these findings. Although susceptibility levels to both compounds remained well above levels correlated with resistance in vivo, ${ }^{5.11}$ these findings suggest that an MDR-like phenotype had been derived in these lines. Alternatively, cross-resistance to halofantrine and susceptibility to chloroquine may be mediated by other mechanisms since efflux of mefloquine has not yet been demonstrated in $P$. falciparum.

The MDR phenotype has been especially difficult to document in vivo since individuals may be coinfected with singly or multiple drug-resistant strains that may be preferentially selected during treatment regimens. Nevertheless, several interesting observations have been noted in the field following treatment failures. ${ }^{4-6,39}$ A treatment failure with enpiroline in an experimental volunteer yielded a post-treatment isolate with increased resistance to halofantrine and mefloquine, and increased susceptibility to chloroquine and quinine. 5 Analysis of recrudescent parasites following treatment failures with mefloquine in Thailand have also demonstrated significant increases in the in vitro resistance to mefloquine, halofantrine, and enpiroline, and significant increases in sensitivity to chloroquine. ${ }^{6.39}$ These findings imply that resistance mechanisms to mefloquine and halofantrine developed by Mef 2.4 in vitro may be similar to mechanisms of resistance that develop in vivo.

Currently, there are few in vitro models available to study the acquisition of antimalarial resistance that may be correlated with the patterns of resistance emerging in field settings. Our results suggest that not only does the Mef 2.4 model mimic drug susceptibility profiles noted in recrudescent parasites in vivo, 5, 6,39 but also appears to parallel, at least in part, the MDR phenotype seen in mammalian tumor cell lines. Progressively resistant parasite lines that tolerate pharmacologic doses of mefloquine provide a unique model system to examine potential biological and molecular processes that may relate to mefloquine resistance. Important areas of investigation with these lines include 1) the study of cross-resistance and collateral sensitivity to related and unrelated compounds, 2) the capacity of reversal agents to restore the efficacy 
of existing antimalarials against these lines, 3) the ability of these parasites to compartmentalize or efflux drug, and 4) the identification of genes such as pfmdrl that may mediate mefloquine resistance in vitro and in vivo.

Acknowledgments: We thank Tamara Bennett for excellent technical assistance. We are grateful to the staff of the Blood Donor Center at Fort Bragg, North Carolina and the American Red Cross for providing blood and plasma.

Financial support: This work was supported by grants from the U.S. Army (DAMD17-87-C-7242), the John Reed Trust, and the North Carolina Biotechnology Center (9213-ARG-0405). This work was also done during the tenure of an established investigator award to Ralph S. Baric from the American Heart Association (AHA-89-0193).

Authors' addresses: Sheila A. Peel and Ralph S. Baric, Department of Epidemiology, CB 7400, McGavranGreenberg Hall, School of Public Health, University of North Carolina, Chapel Hill, NC 27599-7400. Stephen C. Merritt, Department of Microbiology, George Washington University, Washington, DC 20052. Jean Handy, CB 7600, Clinical Microbiology and Immunology Laboratories, UNC Hospitals, Chapel Hill, NC 27514.

Reprint requests: Ralph S. Baric, Department of Epidemiology, CB 7400, McGavran-Greenberg, School of Public Health, University of North Carolina, Chapel Hill, NC 27599-7400.

\section{REFERENCES}

1. Peters $W, 1985$. The problem of drug resistance in malaria. Parasitology 90: 705-715.

2. Centers for Disease Control, 1990. Recommendations for the prevention of malaria among travelers. MMWR Morb Mortal Wkly Rep 39: $1-10$.

3. Bourdreau EF, Webster HK, Pavanand K, Thosingha $L, 1982$. Type-II mefloquine resistance in Thailand. Lancet 11: 1335.

4. Webster LT, Thaithong S, Pavanand K, Yongvanitchit K, Pinswasdi C, Boudreau EF, 1985. Cloning and characterization of mefloquine-resistant P. falciparum from Thailand. Am J Trop Med Hyg 43: 1022-1027.

5. Cosgriff TM, Pamplin CL, Canfield CJ, Willet GP, 1985. Mefloquine failure in a case of falciparum malaria induced with a multidrug-resistant isolate in a non-immune subject. Am J Trop Med Hyg 34: 692-693.

6. Childs GE, Boudreau EF, Wimonwattratee T, Pang L, Milhous WK, 1991. In vitro and clinical correlates of mefloquine resistance of Plasmodium falciparum in eastern Thailand. Am J Trop Med Hyg 44: 553-559.
7. Smrkovski LL, Buck RL, Alcantara AK, Rodriguez CS, Uylangco CV, 1985. Studies of resistance to chloroquine, quinine, amodiaquine and mefloquine among Philippine strains of Plasmodium falciparum. Trans $R$ Soc Trop Med Hyg 79: 37-41.

8. Oduola AMJ, Milhous WK, Salako LA, Walker O, Desjardins RE, 1987. Reduced in vitro susceptibility to mefloquine in West African isolates of Plasmodium falciparum. Lancet ii: 572573.

9. Lambros C, Notsch JD, 1984. Plasmodium falciparum: resistance produced in vitro. Bull World Health Organ 62: 433-437.

10. Oduola AJ, Milhous WK, Weatherly NF, Bowdre JH, Desjardins RE, 1988. Plasmodium falciparum: induction of resistance to mefloquine in cloned strains by continuous drug exposure in vitro. Exp Parasitol 67: 354-360.

11. Milhous WK, Gerena L, Kyle DE, Oduola AMJ, 1989. In vitro strategies for circumventing antimalarial drug resistance. Prog Clin Biol Res 313: 61-72.

12. Peters W, Portus JH, Robinson BL, 1977. The chemotherapy of rodent malaria. XXVIII. The development of drug-resistance to mefloquine (WR 142,490). Ann Trop Med Parasitol 71:419 427.

13. Peters W, Robinson BL, 1991. The chemotherapy of rodent malaria. XLVI. Reversal of mefloquine resistance in rodent Plasmodium. Ann Trop Med Parasitol 85: 5-10.

14. Wilson CM, Serrano AE, Wasley A, Bogenschutz MP, Shankar AH, Wirth DF, 1989. Amplification of a gene related to mammalian mdr gene in drug resistant Plasmodium falciparum. Science 244: 1184-1186.

15. Juliano RL, Ling V, 1976. A surface glycoprotein modulating drug permeability in Chinese hamster ovary cell mutants. Biochim Biophys Acta 455: 152-162.

16. Croop JM, Gros P, Housman DE, 1988. Genetics of multidrug resistance. J Clin Invest 81 : 13031309.

17. Foote SJ, Thompson JK, Cowman AF, Kemp DJ, 1989. Amplification of the multidrug resistance gene in some chloroquine-resistant isolates of $P$. falciparum. Cell 57: 921-930.

18. Foote SJ, Kyle DE, Martin RK, Oduola AMJ, Forsyth K, Kemp DJ, Cowman AF, 1990. Several alleles of the multidrug resistance gene are closely linked to chloroquine resistance in Plasmodium falciparum. Nature 345: 255-258.

19. Wellems TE, Panton LJ, Glutzman IY, do Rosario VE, Gwadz RW, Walker-Jonah A, Krogstad DJ, 1990. Chloroquine resistance not linked to mdrlike genes in a Plasmodium falciparum cross. Nature 345: 253-255.

20. Oduola AMJ, Weatherly NF, Bowdre JH, Desjardins RE, 1988. Plasmodium falciparum: cloning by single-erythrocyte micromanipulation and heterogeneity in vitro. Exp Parasitol 66: 86-95. 21. Trager $W$, Jensen JB, 1976. Human malarial par- 
asites in continuous culture. Science 193: 673675.

22. Haynes JD, Diggs CL, Hines FA, Desjardins RE 1976. Culture of human malarial parasites Plasmodium falciparum. Nature 263: 767-769.

23. Oduola AMJ, Alexander BM, Weatherly NF, Bowdre JH, Desjardins RE, 1985. Use of nonhuman plasma for in vitro cultivation and antimalarial drug susceptibility testing of Plasmodium falciparum. Am J Trop Med Hyg 34: 209-215.

24. Ozols RF, Cowan K, 1986. New aspects of clinical drug resistance: the role of gene amplification and the reversal of resistance in drug refractory cancer. Important Adv Oncol: 129-157.

25. Peters W, 1968. The chemotherapy of rodent malaria. V. Dynamics of drug resistance, part 1: methods for studying the acquisition and loss of resistance to chloroquine by Plasmodium berghei. Ann Trop Med Parasitol 62: 277-287.

26. Desjardins RE, Canfield CJ, Haynes, Chulay JD, 1979. Quantitative assessment of antimalarial activity in vitro by a semiautomated microdilution technique. Antimicrob Agents Chemother 16: 710-718.

27. Remington RD, Schork MA, 1985. The analysis of variance. Remington RD, Schork, MA, eds. Statistics with Applications to the Biological and Health Sciences. Englewood Cliffs, NJ: PrenticeHall, Inc., 165-185, 262-292.

28. Desjardins RE, Pamplin CL, von Bredow J, Barry KG, Canfield CJ, 1979. Kinetics of new antimalarial, mefloquine. Clin Pharmacol Ther 26. 372-379.

29. Chevli R, Fitch CD, 1982. The antimalarial drug mefloquine binds to membrane phospholipids. Antimicrob Agents Chemother 21: 581-586.

30. San George RC, Nagel RL, Fabry ME, 1984. On the mechanism for the red-cell accumulation of mefloquine, an antimalarial drug. Biochem Biophys Acta 803: 174-181.

31. Geary TG, Divo AD, Jensen JB, Zangwill $M$, Ginsburg H, 1990. Kinetic modelling of the response of Plasmodium falciparum to chloroquine and its experimental testing in vitro. Biochem Pharmacol 40: 685-691.

32. Jacobs GH, Aikawa M, Milhous WK, Rabbege JR, 1987. An ultrastructural study of the effects of mefloquine on malarial parasites. Am J Trop Med Hyg 36: 9-14.

33. Zamora JM, Beck WT, 1992. Chloroquine enhancement of anticancer drug cytotoxicity in multiple drug resistant human leukemic cells. Mol Pharmacol 33: 454-462.

34. Beck WT, 1987. The cell biology of multiple drug resistance. Biochem Pharmacol 36: 2879-2887.

35. Thaithong $S, 1983$. Clones of different sensitivities in drug-resistant isolates of Plasmodium falciparum. Bull World Health Organ 61: 709712.

36. Wellems TE, 1992. How chloroquine works. $\mathrm{Na}$ ture 355: 108-109.

37. Slater AFG, Cerami A, 1992. Inhibition by chloroquine of a novel haem polymerase enzyme activity in malaria trophozoites. Nature 355: 167-169.

38. Karcz S, Cowman SK, 1991. Similarities and differences between the multidrug resistance phenotype of mammalian tumor cells and chloroquine resistance in Plasmodium falciparum. Exp Parasitol 73: 233-240.

39. Webster HK, Boudreau EF, Pavanand K, Yongvanitchit K, Pang LW, 1985. Antimalarial drug susceptibility testing of Plasmodium falciparum in Thailand using a microdilution radioisotope method. Am J Trop Med Hyg 34: 228-235. 